\title{
Exposing the hidden half: root research at the forefront of science
}

\author{
Jhonathan E. Ephrath • Tamir Klein • \\ Robert E. Sharp • Naftali Lazarovitch
}

Received: 22 December 2019 / Accepted: 26 December 2019/Published online: 13 January 2020

(C) Springer Nature Switzerland AG 2020

\section{Introduction}

This special section of Plant and Soil contains 12 contributions based on presentations at the 10th Symposium of the International Society of Root Research (ISRR10), which took place in Israel from 8 to 12 July, 2018 (https://www.ortra.com/events/isrr10/Home.aspx). The symposium promoted fundamental understanding of the diverse aspects of root biology. The symposium, titled: "Exposing the Hidden Half - Root Research at the Forefront of Science", assembled multiple disciplines in order to facilitate exploration of novel approaches and investigation of complex processes and mechanisms. The intersections of root physiology, root development, root architecture and root interactions with the environment were tackled by researchers from around the globe through oral presentations, poster sessions and discussions. Basic research at multiple scales

Responsible Editor: Hans Lambers.

\section{J. E. Ephrath $(\bowtie) \cdot$ N. Lazarovitch}

French Associates Institute for Agriculture and Biotechnology of Drylands, Jacob Blaustein Institutes for Desert Research,

Ben-Gurion University of the Negev, Midreshet

Ben-Gurion 8499000, Israel

e-mail: yoni@bgu.ac.il

\section{T. Klein}

Department of Plant and Environmental Sciences, Weizmann Institute of Science, 76100 Rehovot, Israel

\section{R. E. Sharp}

Interdisciplinary Plant Group and Division of Plant Sciences, University of Missouri, Columbia, MO 65211, USA (proteins, cells, tissues and the root system as a whole) and cutting-edge methodologies were highlighted as important means to advance plant health and growth, thereby supporting sustainable and nutritious food production.

\section{Probing the interface}

Beyond providing an anchor to the ground, the root system of terrestrial plant species has two major functions: explore and acquire water, and selectively acquire mineral nutrients from the soil. Soil characteristics from which plants extract nutrients and water are highly heterogeneous, both spatially and temporally.

During the last two decades, increasing attention has been given to studies of the soil and root component of the soil-plant-atmosphere continuum (Fig. 1). This increase has been mainly driven by (i) new techniques available for monitoring root development and function; (ii) the need for studying interactions that occur in the rhizosphere of plants, including different biotic and abiotic factors that affect root growth; and (iii) the chemical component of soil-root interactions.

\section{Absorption of beneficial nutrients}

In order to increase nutritious food production in the world and to meet the requirements of the growing population, application of precise nutrition to crops is essential. Nitrogen $(\mathrm{N})$ and phosphorus $(\mathrm{P})$ are critical determinants of plant growth and productivity. Equally 
Fig. 1 Number of publications per year with the topic of "Root and Soil"

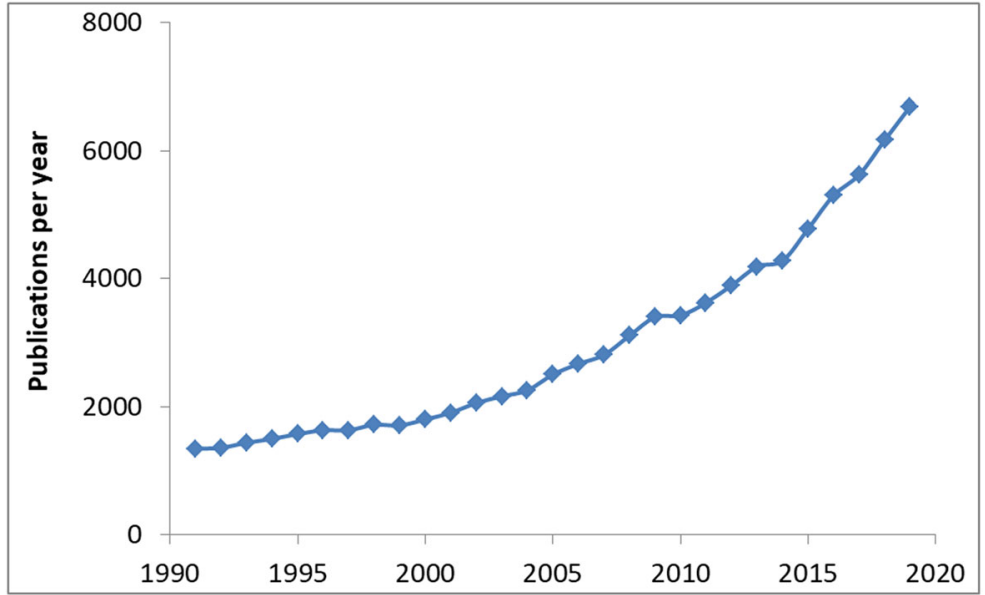

important, $\mathrm{N}$ and $\mathrm{P}$ are key nutrients for ecosystem structure and functioning, affecting physiological processes taking place in the plant, since their availability limits the production of plant biomass and growth (Song et al. 2010). Nitrogen and $P$ fertilization will increase root surface area, root length, and root-shoot mass. Phosphorus is an essential element for many key processes that take place in the plant including photosynthesis, phosphorylation, genetic transfer, and membrane function and the transport of nutrients. Additional information, recent progress and challenges and future perspectives on $\mathrm{P}$ availability can be found in the review of Wang and Lambers (2020).

Different aspects of the effects of $\mathrm{P}$ on root growth and aboveground development are presented in this special issue. Zhou et al. (2020) tested the effects of aboveground environmental conditions on the development of root morphology. Different light intensities under different $\mathrm{P}$ concentrations were examined in maize grown in rain-sheltered field plots. The authors found that under P deficiency and normal light intensity, compared with low light conditions, maize allocated more photosynthates to the roots as sucrose. In a different study by Shi et al. (2020a), the effects of different $P$ levels on peanut growth parameters such as leaf growth, gas exchange and chlorophyll fluorescence were examined. Unlike the previous study, this experiment was conducted in a climate-controlled growth chamber. Under low or excessive $\mathrm{P}$ supplies, a reduction in leaf growth occurred. In addition, unfavorable $\mathrm{P}$ conditions were associated with significant reduction of photosynthesis and photodamage extending beyond PSII. Ding et al. (2020) tested the different effects of
$\mathrm{pH}$ and bicarbonate on Lupinus species. High $\mathrm{pH}$ decreased root growth and nutrient uptake. High bicarbonate diminished the negative effect of high $\mathrm{pH}$ on nutrient translocation. This information is critical to guide breeding of crops growing in calcareous soils. Shi et al. (2020b) examined modifications in root functioning of two Banksia species, of which one is fire-killed and one resprouts after fire, in order to understand their different ecological distributions. They used various experimental platforms such as deep pots, shallow pots and hydroponic experiments to check $\mathrm{P}$ uptake and various root traits. Their findings suggest that tradeoffs in investment and cluster-root functioning support the species' distribution patterns and life histories.

Using a combination of greenhouse and field experiments, Wang et al. (2020) examined if $\mathrm{NO}_{3}{ }^{-}$and $\mathrm{NH}_{4}{ }^{+}$competition and organic acids influence $\mathrm{N}_{2}$ fixation of intercropped crops. They also examined whether intercropping of maize and alfalfa increased the $\mathrm{N}_{2}$ fixation of the maize. They concluded that between 15 and $20 \%$ of the $\mathrm{N}$ fixed by alfalfa was transferred to maize. Liu et al. (2020) investigated in a field study the dynamic root growth of maize intercropped with wheat fertilized with different $\mathrm{N}$ rates. Their findings show that the recovery growth of late-maturing lines involves phenotypic plasticity of maize root architecture.

\section{Toxic elements}

Aluminum toxicity is one of the major limiting factors for crop production under acid soils (Matsumoto and Sivaguru 2008), which occur mainly in developing countries. The acidity is partly due to environmental 
pollution and acid rain. This causes a significant reduction of soil fertility due to the deficiency of essential nutrients such as calcium $(\mathrm{Ca})$, magnesium $(\mathrm{Mg})$, potassium $(\mathrm{K})$ and $\mathrm{P}$, and, on the other hand, high content of harmful and toxic elements such as aluminum (Al) and manganese (Mn). In this special issue, Pooniya et al. (2020) evaluated the impact of an acidic soil with a high $\mathrm{Al}^{3+}$ concentration on root and shoot traits of two durum wheat lines. The introgressed line could grow roots below a depth of $0.25 \mathrm{~m}$, where the soil $\mathrm{pH}$ was low. The total root length and biomass at 42 days after sowing were higher relative to the control line. They concluded that introgression of the $\mathrm{Al}^{3+}$-tolerant allele into durum wheat enabled root growth and proliferation down an acidic soil profile with a high $\mathrm{Al}^{3+}$ concentration. They assumed that under field conditions, where plants need to take up water at greater depths, the differences in aboveground parameters would be amplified.

Osmotic stress from saline irrigation is a worldwide problem affecting roots of crop plants. In this regard, plants may also experience specific toxicity following uptake of excessive sodium ions $\left(\mathrm{Na}^{+}\right)$from the soil. In most plants, $\mathrm{Na}$ is harmful to cellular systems, and if accumulated to toxic levels in the leaves, can severely injure plants through leaf burn and loss of tissue. The integrity of cellular membranes, activities of various enzymes, nutrient acquisition, and function of the photosynthetic apparatus are all prone to the toxic effects of high $\mathrm{Na}^{+}$(Shelef et al. 2010). Perelman et al. (2020) monitored the 'root-felt' $\mathrm{Na}^{+}$by using rhizoslides as a non-invasive method. They studied how transpiration rate, salinity in irrigation water, and root water uptake affect $\mathrm{Na}$ distribution around single roots of tomato. They also interpreted the experimental results by using simulations with a 3-D root system architecture model coupled with water flow and solute transport models. They concluded that changes in $\mathrm{Na}^{+}$concentrations with transpiration rates are most likely caused by root water uptake and ion exclusion. The simulation results indicate that root-scale process models are required to link root system architecture, environmental, and soil conditions with root-felt salinities.

\section{Biotic interactions}

Optimizing plant nutrition through improved understanding of rhizosphere processes is key to a future of higher soil degradation and expectations for decreased fertilizer inputs. To what extent do rhizosphere conditions and root morphology affect soil $\mathrm{P}$ mobilization into plant roots? Partitioning the relative roles of parameters like soil $\mathrm{pH}$, organic anions, and phosphatase enzymes can be highly valuable to the agricultural sector. In this special issue, a field experiment in maize/ alfalfa polyculture shows that root surface area of maize and lateral root volume of alfalfa had the greatest effect on crop P uptake (Sun et al. 2020). In that experiment, soil $\mathrm{pH}$ and organic anions had a secondary effect, still larger than that of phosphatase. Elevated atmospheric $\mathrm{CO}_{2}$ concentration is another future realm of unknown effects. A greenhouse experiment on maize showed that root systems may grow faster, longer and denser in the future (Hiltpold et al. 2020). But no yin without yang: while roots may benefit from the higher carbon availability, delicate biotic interactions in the rhizosphere change as well. The study showed how beneficial soil nematodes become less effective in decreasing insect pest load at elevated $\mathrm{CO}_{2}$. Further research of such biotic interactions will allow fine tuning of rhizosphere design for various objectives. One promising tool in studying such complex interactions is polymer models replicating the microstructure of roots (Kumari et al. 2020). Using this novel approach, researchers showed colonization of root replicates by pathogenic bacteria and nematodes. These fine, artificial replicates help to discriminate the role of microstructure in root-microbe interactions.

\section{Concluding remarks and future directions}

Plant roots provide water and nutrients and are hence the first to experience abiotic and biotic soil stresses. Technologies such as grafting, breeding and genetic engineering can change the root system properties and improve root activity and durability to stresses. Directing the root system characteristics must take into account the environmental factors such as: soil type and depth, irrigation method, water quality, nutrient availability, toxic soil elements, $\mathrm{pH}$. The plant's energetic priorities for determining the root to shoot ratio and investment in altering root architecture should be one of the considerations for designing an optimal root system. In any specific case, one must consider whether the energetic cost to alter the root system is eventually beneficial for the plant. 


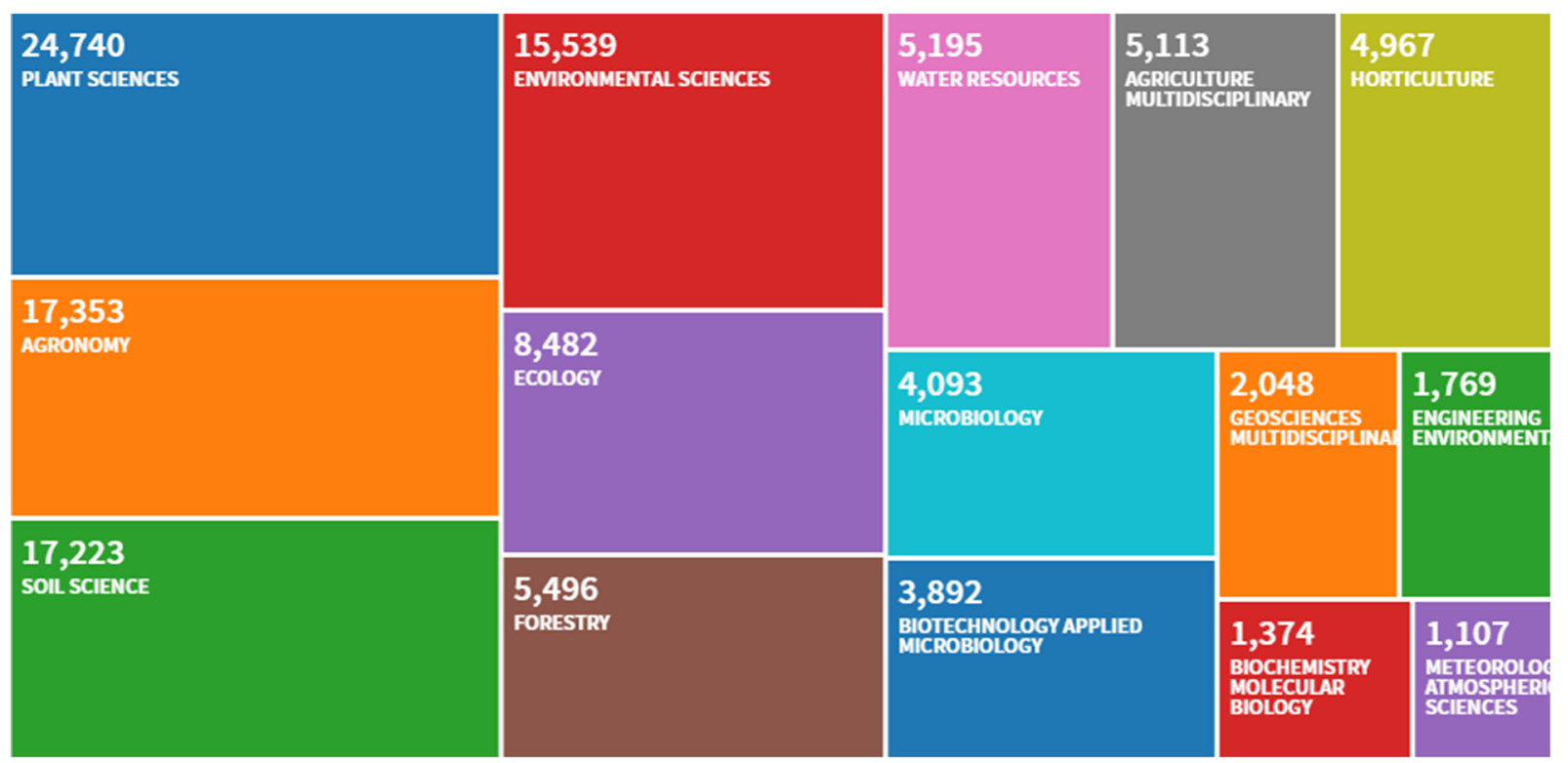

Fig. 2 Category distribution of publications with the topic of "Root and Soil" in the last 30 years

Functional-structural models simulate the relations between root system architectural and hydraulic properties, and the spatio-temporal distributions of water and solutes in the root zone. Such models may help identify optimal plant properties for breeding programs and contribute to increased water and nutrient-use efficiency. Models enable the testing of new hypotheses, as well as sensitivity analyses for root traits and boundary conditions. This approach is useful for breeding programs by decreasing the experimental time and focusing on the critical factors. Nevertheless, for the calibration and validation of these models there is a need for results from the same spatial and temporal resolution. It is, therefore, important to have cross-talk between models and experiments, as they should rely on each other.

Some studies presented in this special issue were done in controlled-environment pot experiments, while others were conducted in the field. The controlledenvironment experiments can help separating between variables. Yet, under these artificial conditions, root structure and function are often altered and exhibit contrasting behavior to field conditions. It is recommended that hypotheses are examined in small-scale controlled environments, which are eventually validated in natural field conditions. With the huge complexity that is associated with field work, research programs should target scaling up the pot experiments to field scale.

Root systems are highly plastic and adjust according to soil conditions. Non-invasive root phenotyping does not disturb root system structures, architecture, and functions within the rhizosphere and bulk soil environments. Studying the particular influence of soils on root development requires the use of imaging methods for various growth media. The rhizosphere can be monitored as a holistic phenotype, which includes the root, for discovery of new traits, selection in breeding, and interventions with management. Non-invasive phenotyping also provides root and rhizosphere dynamics studies. Yet, most of the available techniques are conducted in small-scale column experiments and are cumbersome and expensive. Portable systems that can work in the field are limited and not automatic. Additionally, their image analysis is semiautomatic and time consuming.

Both during the conference and in this special issue, there were a number of contributions on the topic of the rhizosphere microbiome and its role in soil-root processes. This ratio is also reflected in the data presented in Fig. 2, in which only $8 \%$ of the publications that were published with the topic of "root and soil" were associated with microbiology journals. The rhizosphere microbiome is an evolving topic that can be a platform for innovative studies combing several disciplines, and we expect to see it further developing.

Acknowledgments This conference was partially supported by the Research Workshop of the Israel Science Foundation (ISF), Israeli Ministry of Science and Technology, Jacob Blaustein Center for Scientific Cooperation, and Israeli Ministry of Agriculture 
and Rural Development (Eugene Kandel Knowledge Centers) as part of the program 'The Root of the Matter: The Root Zone Knowledge Center for Leveraging Modern Agriculture', ICL group - Israel, Springer publishing company.

\section{References}

Ding W, Clode PL, Lambers H (2020) Effects of pH and bicarbonate on the nutrient status and growth of three Lupinus species. Plant Soil

Hiltpold I, Moore BD, Johnson SN (2020) Elevated atmospheric carbon dioxide concentrations alter root morphology and reduce the effectiveness of entomopathogenic nematodes. Plant Soil

Kumari P, Ginzburg N, Sayas T, Saphier S, Bucki P, Brown Miyaya S, Caldwell DL, Iyer-Pascuzzi AS, Kleiman M (2020) A novel method using biomimetic platform for studying root-environment interaction. Plant Soil

Liu YX, Sun JH, Zhang FF, Li L (2020) The plasticity of root distribution and nitrogen uptake contributes to recovery of maize growth at late growth stages in wheat/maize intercropping. Plant Soil

Matsumoto H, Sivaguru M (2008) Advances in the aluminum toxicity and tolerance of plants for increased productivity in acid soils. In Soil Contamination: New Research, ed. AN Dubois, pp. 1-42. Nova Science Publishers, New York

Perelman A, Jorda H, Vanderborght J, Lazarovitch N (2020) Tracing root-felt sodium concentrations under different transpiration rates and salinity levels. Plant Soil

Pooniya V, Palta JA, Chen Y, Delhaize E, Siddique KHM (2020) .Impact of the TaMATE1B gene on above and below-ground growth of durum wheat grown on an acid and Al3+-toxic soil. Plant Soil
Shelef O, Lazarovitch N, Rewald B, Golan-Goldhirsh A, Rachmilevitch S (2010) Root halotropism: salinity effects on Bassia indica root. Plant Biosyst 144(2):471-478. https://doi.org/10.1080/11263501003732001

Shi J, Strack D, Albornoz FE, Han Z, Lambers H (2020a) Differences in investment and functioning of cluster roots account for different distributions of Banksia attenuate and B. sessilis, with contrasting life history. Plant Soil

Shi Q, Pang J, Yong JWH, Bai C, Pereira CG, Song Q, Wu D, Dong Q, Cheng X, Wang F, Zheng J, Liu Y, Lambers H (2020b) Phosphorus-fertilisation has differential effects on leaf growth and photosynthetic capacity of Arachis hypogaea. L. Plant Soil

Song CJ, Ma KM, Qu LY, Liu Y, Xu XL, Fu BJ, Zhong JF (2010) Interactive effects of water, nitrogen and phosphorus on the growth, biomass partitioning and water-use efficiency of Bauhinia faberi seedlings. J Arid Environ 74:1003-1012

Sun B, Gao Y, Wu X, Ma H, Zheng C, Wang X, Zhang H, Li Z, Yang $H$ (2020) The relative contributions of $\mathrm{pH}$, organic anions, and phosphatase to rhizosphere soil phosphorus mobilization and crop phosphorus uptake in maize/alfalfa polyculture. Plant Soil

Wang Y, Lambers H (2020) Root-released organic anions in response to low phosphorus availability: recent progress, challenges and future perspectives. Plant Soil

Wang X, Gao Y, Zhang H, Shao Z, Baoru S, Gao Q (2020) Enhancement of rhizosphere citric acid and decrease of NO3-/NH4+ ratio by root interactions facilitate $\mathrm{N}$ fixation and transfer. Plant Soil

Zhou T, Wang L, Sun X, Wang X, Chen Y, Rengel Z, Liu W, Yang W (2020) Light intensity influence maize adaptation to low P stress by altering root morphology. Plant Soil

Publisher's note Springer Nature remains neutral with regard to jurisdictional claims in published maps and institutional affiliations. 